\title{
Diabetes Health Services in Sri Lanka: Development of a Quality Index
}

\author{
Nethmini VJ Thenuwara ${ }^{1}$, Christopher M Reid ${ }^{1,2}$, Pushpa Fonseka ${ }^{3}$, Baki Billah ${ }^{4}$, \\ Champika Wickramasinghe ${ }^{5} \&$ Andre MN Renzaho ${ }^{4,6}$ \\ ${ }^{1}$ Centre of Cardiovascular Research and Education in Therapeutics, Monash University, Melbourne, Victoria, \\ Australia \\ ${ }^{2}$ School of Public Health, Curtin University, Perth, Western Australia \\ ${ }^{3}$ Department of Community Medicine, Faculty of Medical Sciences, University of Sri Jayewardenapura, Sri \\ Lanka \\ ${ }^{4}$ Department of Epidemiology and Preventive Medicine, Monash University, Melbourne, Victoria, Australia \\ ${ }^{5}$ Management Development and Planning Unit, Ministry of Health, Sri Lanka \\ ${ }^{6}$ School of Social Sciences and Psychology, University of Western Sydney, New South Wales, Australia \\ Correspondence: Prof CM Reid, CCRE Therapeutics, School of Public Health and Preventive Medicine, Monash \\ University, 553 St Kilda Rd, Melbourne, Vic 3004, Australia. Tel: 61-03-9903-0752. E-mail: \\ Chris.Reid@monash.edu
}

Received: October 18, 2018 Accepted: February 28, 2019 Online Published: March 12, 2019

doi:10.5539/gjhs.v11n4p41 URL: https://doi.org/10.5539/gjhs.v11n4p41

\begin{abstract}
Background: Diabetes mellitus is a major public health issue in Sri Lanka and across the globe. Patients with diabetes mellitus (DM) need long term comprehensive care. Quality of care for DM varies in different settings. Service quality assessment leads to identifying service areas that may benefit from appropriate intervention in order to achieve better health outcomes. The aim of this study was to develop and validate an instrument to measure the quality of services provided for patients with DM attending medical and diabetic clinics in state hospitals of Sri Lanka.

Methods: A 'Care for DM Quality of services' (CD QS) instrument comprised of 8 subscales: routine services, glycaemic control, Blood Pressure and lipid control, weight control, annual screening, patient empowerment, recording of information and functional aspects was developed and validated. Trained research assistants collected data from 100 volunteer patients attending four diabetic clinics two each at secondary and tertiary level hospitals. Construct validity was established by multi-trait scaling analysis and known group comparisons. Internal consistency was assessed by item-total correlations and Cronbach's alpha. Cut off levels to classify the hospital clinic as 'good', 'moderate' or 'poor' performance were determined by the average score in each subscale being above mean $+\mathrm{SD}$ (good), between mean $\pm \mathrm{SD}$ (moderate), and below the mean $-\mathrm{SD}$ (poor) respectively.

Results: Multi-trait scaling analysis of items showed highest correlation with its own subscale compared to the other subscales. Significantly higher mean scores $(\mathrm{p}<0.05)$ for all the subscales were observed in tertiary level clinics compared to the secondary level. Internal consistency of 'CD QS' was good with Cronbach's alpha of 0.9. Intra Class Correlation Coefficients were over 0.9 for all subscales with confidence intervals ranging from 0.8 to 2.9 suggestive of good inter-rater reliability.

Conclusions: 'CD QS' is a valid and reliable tool to assess both functional and technical quality of follow up care provided for patients with DM. This facilitates regular quality assessment of DM care thus identifying the gaps and improving the service quality. Further implementation and testing for clinical usefulness and acceptability will determine the tools application in the healthcare setting.
\end{abstract}

Keywords: diabetic clinic, diabetes mellitus, healthcare, quality, service

\section{Introduction}

Quality in health care is a major concern in both resource constraint and well-developed health systems as it is closely associated with improved patient care experience and health outcomes. Furthermore, health systems have to optimize the utilization of resources to expand and improve health services with the aim of achieving best 
possible results with population coverage (World Health Organization, 2006). Healthcare quality has two distinct facets: technical quality and functional quality (Donabedian, 1988; Grönroos, 1984).

Technical quality refers to the accuracy of medical diagnoses and procedures while functional quality refers to the manner in which the health services are delivered. It includes tangibility, reliability, responsiveness, assurance and empathy (Parasuraman, Zeithaml, \& Berry, 1985).

Measurement of quality of care is important to ensure delivery of optimal care to patients, inform professionals of their effort and allocate limited resources (Donabedian, 1988; Wisniewski \& Wisniewski, 2005). Quality measurement instruments can be developed for inputs, process and outcome or according to various dimensions of quality (Campbell, Roland, \& Buetow, 2000; World Health Organization, 2006). As Donabedian (1988) noted, organizational quality has been assessed according to a model consisting of structure, process and outcome (Donabedian, 1988). 'Structure' denotes the availability of facilities, equipment, human resources and other supplies essential for better service provision. Availability of services and how they are delivered are included in the 'process' measures. 'Outcome' measures the impact of the care on health status. Various data collection methods have been used in quality assessment such as direct observation of the performance of health worker or indirect assessment of performance via testing of providers, health worker interview, patient exit interview or record review (Families USA \& The Voice for Health Care Consumers, 2014; Peabody, Taguiwalo, Robalino, \& Frenk, 2006). Although the service delivery and measurement of quality in healthcare settings have focussed on the prevention and treatment of communicable diseases in low and middle income countries, it is yet to be integrated into a system of managing non-communicable diseases which continue to dictate active care co-ordination (Kiflie, Jira, \& Nigussie, 2011; World Health Organization, 2002).

The quality service provision for chronic illnesses such as Diabetes Mellitus (DM) which is becoming pandemic and requiring continuous medical care is essential. The chronic nature, the severity of its complications and the means required to control them impose a high cost to the patient, family as well as to the health system (Grandy \& Fox, 2008; World Health Organization, 2004). Substantial reduction of long term complications of DM can be achieved by provision of optimal health care (UK Prospective Diabetes Study Group, 1998).

Thus, the management of DM is not merely lowering glucose, but overall reduction of the risk factors for diabetic complications, which includes the control of blood pressure and blood lipids. This requires lifelong medical care and ongoing patient self-management education (Wild, Roglic, Green, Sicree, \& King, 2004; World Health Organization, 2004). However, poor service quality leads to decreased uptake and utilization of services, poor continuity and compliance (McQuestion, 2006). To enable patient self-management, issues such as health literacy, education and empowerment (a willingness to be involved in decision making about treatment and lifestyle choices) are important educational targets (World Health Organization, 2004).

Most indicators for quality of follow up care for DM have been developed in industrialized countries, with standard national performance measures adopted in the United States of America (USA) in 1998, informed by the Diabetes Quality Improvement Project. These indicators were further refined by the 2003 USA Research and Development Health, which led to the development of clinical indicators for 19 common conditions including DM (McGlynn et al., 2003). The United Kingdom National Health Services 'Quality and Outcomes Framework' proposes five main quality domains: clinical, public health, additional public health services, quality and productivity and patient experience (National Health Services, 2015). However, all these indicators have been developed in industrialized countries, and there is an urgent need to adapt or develop and test quality improvement measures for use in resource constraint settings.

\subsection{Outpatient Care for Diabetes Mellitus in Sri Lanka}

Chronic diseases are becoming the leading causes of deaths in Sri Lanka. In 1945 cardiovascular diseases and DM accounted for $3.5 \%$ and $0.5 \%$ of all deaths. However this had increased to $10 \%$ and $2.4 \%$ respectively by 2001 and DM accounts for greater proportion of bed days and inpatient cost (Rannan-Eliya, Anuranga, Brearley, Elwalagedara, \& Abeykoon, 2010). Katulanda et al (Katulanda et al., 2008) has projected that prevalence of DM in Sri Lanka will increase from $10.3 \%$ to $13.9 \%$ by 2030 . Care for DM in Sri Lanka is delivered at government and private sector hospitals as well as by general practitioners. No data is available for the utilization of services and care provision. Less information is available on care provided for patients with DM at curative care institutions especially at clinic setting due to unavailability of surveillance system or morbidity data of patients attending outpatient departments.

Most state hospitals conduct clinics for long term care of patients with DM and innumerable numbers are being followed up in those clinics. However, a routine data system or a standard procedure is not available to assess the 
provision of care or to examine the effectiveness of services. There is a paucity of studies on service quality for follow up care for patients with DM in primary, secondary and tertiary care settings in Sri Lanka. Therefore the aim of this study was to develop an instrument that would measure technical and functional quality of care for patients with DM attending medical and diabetic clinics in state hospitals of Sri Lanka.

\section{Methods}

\subsection{Study Design and Setting}

A cross-sectional study was carried out in the Western Province which consists of Colombo, Kalutara and Gampaha Districts and spans over an area of 3,593 square kilometres. A total of 5, 837, 294 population live in the Western Province, of whom $18.6 \%$ are diabetic (Katulanda, Rathnapala, Sheriff, \& Matthews, 2012). The state sector curative care institutions have been categorized in to 3 levels based on the facilities and medical specialities:

1) Primary care institutions: Divisional hospital Type A, B \& C and Primary Care Units provide outpatient care and basic inpatient care

2) Secondary care institutions: District General and District Base hospitals provide major specialities (Medicine, Paediatrics, Surgery and Obstetrics) in addition to few minor specialities

3) Tertiary care institutions: Teaching hospitals and specialized hospitals with all minor specialities including Endocrinologists (Ministry of Health Sri Lanka, 2008).

There are 3 tertiary level and 8 secondary level hospitals situated in the Western Province conducting diabetic clinics. The study was conducted in four diabetic clinics of two randomly selected tertiary and two secondary care hospitals in the Western Province, Sri Lanka. The average daily clinic attendance was 256-284 patients.

\subsection{Participants and Procedure}

The sample consisted of 100 patients aged 20 years or more and having DM for a minimum period of 18 months and followed up in the diabetic clinic for a period of $>18$ months duration. Written permission was obtained from health authorities prior to data collection and ethical approval was granted by the Ethics Review Committee, Faculty of Medical Sciences, University of Sri Jayewardenapura, Sri Lanka. Our sampling occurred at two different stages.

At the setting level clinics were randomly selected and within the setting, individuals were asked to volunteer on a random basis. Twenty five patients each were recruited from selected clinics, two clinics each at secondary and tertiary level which consists of 50 patients in each category of hospital. Data was collected using two approaches. The first approach was non-participatory observation technique and supplemented by examination of the patient records as all services are not provided in a particular clinic day. Some services have to be given during a particular time period (eg: annual screening) and may not be observed during the day of assessment. Therefore notes of the clinic record were examined for preceding one year period to verify the service provision. The second approach was interviewing the patient for demographic and socioeconomic information via Interviewer Administered Questionnaire

(IAQ). Four research assistants were trained to collect data with minimum attention of the service provider during observations. The dates for data collection were randomly selected after preparing a common calendar consists of all the clinic days of selected clinics and fixed without overlapping the clinic days. One clinic had to be visited three times as it took much time to observe a particular patient from the time of registration to leaving the pharmacy. Data collection was commenced on a randomly selected clinic day and continued on each consecutive clinic day until the required sample is drawn. Patients were recruited from the registration counter on first come first served basis with the first patient registered for that particular clinic session and if the criteria for inclusion were fulfilled with consent given. Data collector followed up each enrolled patient at all service stations throughout the period. A few observations were made for non-recruited patients prior to observation of the enrolled patient to minimize the observer bias. Once all the services were observed for a particular patient subsequent patient was recruited from the registration counter. Scores for all observations were entered on the 'Care for DM Quality of services' (CD QS) checklist.

Administering of IAQ and examination of the clinic documents were performed while the patient was awaiting to receive some services as there was overcrowding in these clinics.

\subsection{Scale Development Process}

We developed the instrument 'Care for DM Quality of services' (CD QS) to measure the quality of services 
provided to patients with DM attending state diabetic and medical clinics in Sri Lanka according to the guidelines described in "Health Measurement Scales; A guide to their development and use" (Streiner \& Norman, 2003).

The 'preliminary list of items' was developed through extensive literature review and interviewing Key Informants and patients. Literature review was carried out to identify the available instruments and questionnaires on quality of outpatient care of DM. Face to face interviews with Key Informants were carried out with experts via an interviewing format. Medical Specialists, Medical Administrators and Public Health Specialists involved in quality improvement programmes and service provision for DM were interviewed to identify the essential aspects of follow up care for DM. Prior appointments were made with the key informants and the interviews were carried out at a place convenient for the interviewee. After explaining the purpose of the interview the discussion was initiated with open ended key questions. The format was used to ensure all aspects were covered in the discussion. In depth interviews were carried out in ten patients who had been followed up in the diabetic clinic of a Teaching hospital to gather patient's perspective on quality service provision. Identification of existing standards with cut off values was carried out through literature review including guidelines of American Diabetes Association (American Diabetes Association, 2012), International Diabetes Federation (International Diabetes Federation, 2013), and National Clinical Guidelines developed for Sri Lanka by a panel of experts in the local setting (Ministry of Healthcare and Nutrition Sri Lanka, 2007). The required standards consisting of the essential aspects of follow up care for DM was listed out considering the appropriateness and feasibility in Sri Lankan government clinic setting.

Following the analysis of items, items which showed similarity to another item were deleted. The items and standards were matched to form an initial list of 54 items. These items were subjected to Modified Delphi technique involving three rounds. The experts consisted of Consultant Physicians (6), Endocrinologists (4), Medical Administrators (3) and Public Health Specialists in the Non Communicable Disease Unit (2). In round one, the experts were emailed the list of items and they rated them on a four point scale: 4 - Very important, 3 Important, 2 - Less important and 1 - Not important. Items rated as 'very important' and 'important' were resent to the same experts in round two with the responses of the previous round. Consensus was achieved at the third round and items scored high as very important and important with a mean score of 3 or more were retained in the checklist. With the modified Delphi technique, the items were reduced to 44 . The quality of the draft checklist was assessed by the same experts for ambiguity, double- barreled questions, jargon and value laden words thus ensuring the judgemental validity (face, content and consensual). It was decided to assign scores for each response as follows: service is not applicable-0, service is not provided-1, service is provided but it does not meet the standards-2, service is provided and meets the standards-3. Defining 'standards' reduces observer bias while assessing the practice variation. Feasibility and time taken to complete the checklist were assessed by pretesting in a health facility and necessary changes were made accordingly.

\subsection{Scoring of Items and Cutoffs for the Services Checklist}

There are two approaches for combining individual items to a scale. One way is to simply add the scores of individual items assuming that items are equally important in contributing to the total score. The other way is to weigh items by a factor which would reflect its greater importance. Evidence shows that when there are at least 40 items in a scale, differential weighting contributes relatively minute effect, except added complexity for the scorer (22). As this scale consists of more than 40 items and all those items were considered equally important in proper patient care, it was decided to give equal scores to all items. The individual items under each subscale were summed to obtain the subscale score for each patient and the mean score was calculated for each hospital clinic. Each hospital was categorized as performing good, moderate or poor in each subscale according to the average score obtained and cut offs were determined as follows: 'good' performing if the score of the hospital had mean + SD or higher, moderate if the score falls between mean and mean + SD (excluded) and poor if the score falls below the mean score.

\subsection{Derived Measures}

'Care for DM Quality of services' (CD QS) instrument had 44 items under the 8 subscales: routine services (6), glycaemic control (3), Blood Pressure and lipid control (5), weight control (4), annual screening (6), patient empowerment (10), recording of information (5) and functional aspects (5). Items of the CD QS according to the mode of observation are given in Table 1. 
Table 1. Items of the services checklist according to the mode of observation

\begin{tabular}{|c|c|c|c|c|c|}
\hline \multirow[b]{2}{*}{ Item } & \multicolumn{2}{|c|}{ Observation } & \multirow[b]{2}{*}{ Item } & \multicolumn{2}{|c|}{ Observation } \\
\hline & 苞 & 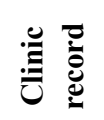 & & 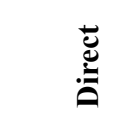 & 苋 \\
\hline $\begin{array}{l}\text { Routine care } \\
\text { Contact with Medical Officer }\end{array}$ & $\sqrt{ }$ & & $\begin{array}{l}\text { Annual screening for } \\
\text { complications }\end{array}$ & & \\
\hline $\mathrm{MO}^{1}$ inquire presenting complaints & $\sqrt{ }$ & & Annual $\mathrm{ECG}^{4}$ & & $\sqrt{ }$ \\
\hline Record results of investigations & $\sqrt{ }$ & & Annual PAD ${ }^{5}$ & & $\sqrt{ }$ \\
\hline Inquire food intake & $\sqrt{ }$ & & Annual screening for retinopathy & & $\sqrt{ }$ \\
\hline Inquire compliance with medication & $\sqrt{ }$ & & $\begin{array}{l}\text { Annual screening for proteinuria } \\
\text { Annual serum Creatinine }\end{array}$ & & $\begin{array}{l}\sqrt{ } \\
\sqrt{ }\end{array}$ \\
\hline Inquire on self-foot care & $\sqrt{ }$ & & Annual examination of feet & & $\sqrt{ }$ \\
\hline Glycaemic control & & & Patient empowerment & & \\
\hline $\begin{array}{l}\text { MO review glycaemic control } \\
\text { Action for high blood glucose }\end{array}$ & $\begin{array}{l}\sqrt{ } \\
\sqrt{ }\end{array}$ & $\begin{array}{l}\sqrt{ } \\
\sqrt{ }\end{array}$ & $\begin{array}{l}\text { Group \& individual health } \\
\text { education }\end{array}$ & $\sqrt{ }$ & $\sqrt{ }$ \\
\hline Annual blood HbA1C & & $\sqrt{ }$ & Health Education at current visit & $\sqrt{ }$ & \\
\hline BP \& lipid control & & & Using at least one $\mathrm{HE}^{6}$ material & $\sqrt{ }$ & \\
\hline Measuring BP and recording & $\sqrt{ }$ & $\sqrt{ }$ & Interactive $\mathrm{HE}$ activity & $\sqrt{ }$ & \\
\hline Action taken for high BP & $\sqrt{ }$ & $\sqrt{ }$ & Information on foot care & $\sqrt{ }$ & $\sqrt{ }$ \\
\hline $\begin{array}{l}\mathrm{ACEI}^{2} \text { prescribed to all with reported } \\
\text { hypertension }\end{array}$ & & $\sqrt{ }$ & $\begin{array}{l}\text { Perform \& record dietary } \\
\text { assessment }\end{array}$ & $\sqrt{ }$ & $\sqrt{ }$ \\
\hline $\begin{array}{l}\text { Annual lipid } \quad \text { profile } \\
\text { Lipid lowering therapy }\end{array}$ & & $\begin{array}{l}\sqrt{ } \\
\sqrt{ }\end{array}$ & $\begin{array}{l}\text { Provision of access to a } \\
\text { dietician/ } \mathrm{NO}^{7}\end{array}$ & $\sqrt{ }$ & $\sqrt{ }$ \\
\hline Weight control & & & Proper advice on food intake & $\sqrt{ }$ & $\sqrt{ }$ \\
\hline Annual $\mathrm{BMI}^{3}$ assessment & & $\sqrt{ }$ & $\begin{array}{l}\text { Advice on regular physical } \\
\text { activity }\end{array}$ & $\sqrt{ }$ & $\sqrt{ }$ \\
\hline $\begin{array}{l}\text { Remark high } \quad \text { BMI } \\
\text { Refer dietary guidance for high }\end{array}$ & & $\begin{array}{l}\sqrt{ } \\
\sqrt{ }\end{array}$ & $\begin{array}{l}\text { Advice on dosage frequency of } \\
\text { medicines }\end{array}$ & $\sqrt{ }$ & \\
\hline BMI & & & Functional aspects & & \\
\hline Calculation of ideal body weight & & $\sqrt{ }$ & $\begin{array}{l}\text { Polite reception by health } \\
\text { worker }\end{array}$ & $\sqrt{ }$ & \\
\hline $\begin{array}{l}\text { Recording of information } \\
\text { General information }\end{array}$ & & $\sqrt{ }$ & $\begin{array}{l}\text { Service provision according to } \\
\text { appointment }\end{array}$ & $\sqrt{ }$ & \\
\hline Diagnosis of diabetes & & $\sqrt{ }$ & Instruction for patients & $\sqrt{ }$ & \\
\hline $\begin{array}{l}\text { Co-morbidities } \\
\text { Risk factors }\end{array}$ & & $\begin{array}{l}\sqrt{ } \\
\sqrt{ }\end{array}$ & $\begin{array}{l}\text { MO Communicates well with } \\
\text { the patient }\end{array}$ & $\sqrt{ }$ & \\
\hline Physical activity & & $\sqrt{ }$ & Date, time for next clinic visit & $\sqrt{ }$ & \\
\hline
\end{tabular}

1- Medical Officer, 2- Angiotensin Converting Enzyme Inhibitor or Angiotensin Receptor Blocker, 3- Body Mass Index, 4Electrocardiogram, 5- Peripheral Arterial Disease, 6- Health Education, 7- Nursing Officer.

\subsection{Statistical Analysis}

Data was analysed using the IBM SPSS (Statistical Package for Social Sciences) version 20.0. Homogeneity of the CD QS was established by item-total correlations. Construct validity of the services checklist was examined by assessment of the hypothesized scale structure via multi-trait scaling analysis and known group comparisons. Multi-trait scaling analysis was based on item-scale correlations (Hays, Hayashi, Carson, \& Ware, 1988). The item-scale correlations were analysed using Spearman's correlation coefficient. Known group comparison was 
based on the hypothesis that patients attending diabetic clinics at tertiary level with more facilities and under the supervision of a consultant endocrinologist would obtain more quality care thus higher scores in service delivery compared to other levels. Therefore mean total scores for each subscale obtained by patients attending diabetic clinics at tertiary level were compared to those attending secondary level diabetic clinics applying independent sample t test. Reliability assessment of the services checklist comprised of calculating the Cronbach's alpha coefficient of each subscale and item total correlations between each item and the subscale. Inter observer reliability for each subscale was assessed using intra class correlation coefficient. Test-retest reliability was assessed for the services checklist. To derive on cut off levels of the CDQS, average of items under each subscale were calculated.

\section{Results}

Forty three out of 44 items in the eight subscales showed a correlation of 0.4 or more with its own subscale and correlated more strongly with its own subscale compared to the other subscales (Table 2). Significantly higher $(\mathrm{p}<0.05)$ mean scores for all 8 subscales were observed in patients attending tertiary level diabetic clinics compared to secondary level as shown in Table 3.

In the reliability assessment, overall Cronbach's alpha was 0.96 and 6 (75\%) subscales (routine services, weight control, annual screening, patient empowerment, recording of information and functional aspects) had Cronbach's alpha of 0.7 or greater showing good internal consistency (Table 4). Intra class correlation coefficient of all subscales among the observers ranged from 0.90 to 98.0 with narrow confidence intervals (Table 3). Statistically significant correlation was observed between the two groups of observers on all eight subscales on the services checklist thus confirming good inter-observer reliability. Summary scores of each subscale are shown in Table 4.

Patient empowerment received the highest score $(17.4+6.2)$ followed by routine care $(12.8+3.8)$. Given that number of items are minimum, glycaemic control received the lowest score $(6.3+1.31)$. Clinics were further categorized as having poor, moderate or good quality of services for each subscale and the results are presented in Table 5 .

The quality of services in all aspects was 'poor' in hospitals "A" and "B". Good quality services were not provided for routine care, BP and lipid control, weight management and patient empowerment at any clinic. Overall the hospital "D" was providing better quality services followed by hospital "C".

Table 2. Item-scale correlations for the services checklist

\begin{tabular}{|c|c|c|c|c|c|c|c|c|c|}
\hline Item & 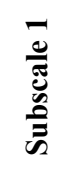 & 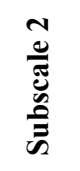 & 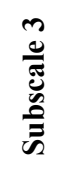 & $\begin{array}{l}+ \\
\stackrel{0}{\tilde{J}} \\
\text { है } \\
\stackrel{\Xi}{\Xi}\end{array}$ & 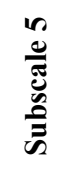 & 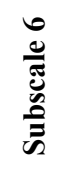 & & 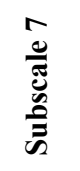 & 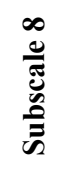 \\
\hline \multicolumn{10}{|l|}{ Subscale 1 - Routine care } \\
\hline Contact with $\mathrm{MO}^{1}$ & 0.67 & 0.33 & 0.29 & 0.20 & 0.42 & 0.33 & & 0.38 & 0.37 \\
\hline MO inquire presenting complaints & 0.75 & 0.38 & 0.28 & 0.33 & 0.44 & 0.31 & & 0.44 & 0.33 \\
\hline Record results of investigations & 0.73 & 0.23 & 0.29 & 0.26 & 0.43 & 0.37 & & 0.48 & 0.32 \\
\hline Inquire food intake & 0.78 & 0.42 & 0.21 & 0.47 & 0.65 & 0.57 & & 0.64 & 0.59 \\
\hline Inquire compliance with medication & 0.81 & 0.44 & 0.14 & 0.31 & 0.49 & 0.40 & & 0.41 & 0.50 \\
\hline Inquire on self-foot care & 0.71 & 0.38 & 0.36 & 0.37 & 0.60 & 0.62 & & 0.46 & 0.56 \\
\hline \multicolumn{10}{|l|}{ Subscale 2 - Glycaemic control } \\
\hline MO review glycaemic control & 0.37 & 0.71 & 0.21 & 0.31 & 0.33 & 0.33 & & 0.32 & 0.39 \\
\hline Action taken for high blood glucose & 0.15 & 0.65 & 0.12 & 0.12 & 0.18 & 0.30 & & 0.10 & 0.19 \\
\hline Annual blood HbA1C & 0.45 & $\mathbf{0 . 8 0}$ & 0.31 & 0.46 & 0.60 & 0.52 & & 0.65 & 0.73 \\
\hline \multicolumn{10}{|l|}{ Subscale 3-BP \& lipid control } \\
\hline Measuring $\mathrm{BP}$ and recording & & 0.15 & 0.29 & 0.46 & 0.11 & 0.01 & 0.11 & 0.10 & 0.10 \\
\hline Action taken for high $\mathrm{BP}$ & & 0.24 & 0.17 & 0.53 & 0.21 & 0.29 & 0.20 & 0.30 & 0.31 \\
\hline
\end{tabular}




\begin{tabular}{|c|c|c|c|c|c|c|c|c|}
\hline $\mathrm{ACEI}^{2}$ prescribed to all with reported hypertension & 0.21 & 0.18 & 0.58 & 0.12 & 0.39 & 0.29 & 0.22 & 0.24 \\
\hline Annual lipid profile (Total cholesterol in primary level) & 0.10 & 0.10 & 0.66 & 0.19 & 0.04 & 0.15 & 0.14 & 0.16 \\
\hline Initiation of lipid lowering therapy & 0.26 & 0.21 & 0.62 & 0.36 & 0.33 & 0.33 & 0.34 & 0.21 \\
\hline \multicolumn{9}{|l|}{ Subscale 4 - Weight control } \\
\hline Annual $\mathrm{BMI}^{3}$ assessment & 0.47 & 0.44 & 0.24 & 0.95 & 0.59 & 0.46 & 0.57 & 0.58 \\
\hline Remark high BMI & 0.26 & 0.28 & 0.15 & 0.84 & 0.39 & 0.33 & 0.41 & 0.36 \\
\hline Refer dietary guidance for high BMI & 0.29 & 0.33 & 0.30 & 0.91 & 0.48 & 0.41 & 0.46 & 0.44 \\
\hline Calculation of ideal body weight & 0.36 & 0.29 & 0.20 & 0.89 & 0.49 & 0.36 & 0.47 & 0.44 \\
\hline \multicolumn{9}{|l|}{ Subscale 5 - Annual screening for complications } \\
\hline Annual $\mathrm{ECG}^{4}$ & 0.44 & 0.36 & 0.20 & 0.42 & 0.72 & 0.53 & 0.53 & 0.44 \\
\hline Annual PAD ${ }^{5}$ & 0.71 & 0.57 & 0.34 & 0.57 & 0.95 & 0.76 & 0.76 & 0.69 \\
\hline Annual screening for retinopathy & 0.58 & 0.52 & 0.37 & 0.47 & 0.81 & 0.73 & 0.64 & 0.61 \\
\hline Annual screening for proteinuria & 0.51 & 0.35 & 0.26 & 0.45 & 0.78 & 0.62 & 0.62 & 0.58 \\
\hline Annual serum creatinine & 0.67 & 0.51 & 0.26 & 0.51 & 0.88 & 0.69 & 0.71 & 0.66 \\
\hline $\begin{array}{l}\text { Annual examination of feet including screening for } \\
\text { neuropathy }\end{array}$ & 0.66 & 0.48 & 0.28 & 0.56 & 0.93 & 0.71 & 0.75 & 0.67 \\
\hline \multicolumn{9}{|l|}{ Subscale 6 - Patient empowerment } \\
\hline Group \& individual health education & 0.51 & 0.58 & 0.42 & 0.42 & 0.71 & 0.87 & 0.57 & 0.62 \\
\hline Health Education at current visit & 0.49 & 0.50 & 0.32 & 0.41 & 0.73 & 0.87 & 0.60 & 0.59 \\
\hline Using at least one $\mathrm{HE}^{6}$ material & 0.60 & 0.49 & 0.46 & 0.46 & 0.78 & 0.86 & 0.67 & 0.66 \\
\hline Interactive $\mathrm{HE}$ activity & 0.38 & 0.36 & 0.37 & 0.31 & 0.49 & 0.64 & 0.36 & 0.44 \\
\hline Information on foot care & 0.64 & 0.57 & 0.54 & 0.53 & 0.76 & 0.85 & 0.71 & 0.69 \\
\hline Perform \& record dietary assessment & 0.53 & 0.56 & 0.45 & 0.49 & 0.70 & 0.77 & 0.58 & 0.58 \\
\hline Provision of access to a dietician/ $/ \mathrm{NO}^{7}$ & 0.28 & 0.30 & 0.23 & 0.21 & 0.48 & 0.71 & 0.34 & 0.41 \\
\hline Proper advice on food intake & 0.45 & 0.44 & 0.36 & 0.32 & 0.59 & 0.84 & 0.39 & 0.46 \\
\hline Advice on regular physical activity & 0.32 & 0.42 & 0.22 & 0.24 & 0.43 & 0.60 & 0.40 & 0.38 \\
\hline Advice on dosage frequency of medicines & 0.21 & 0.27 & 0.10 & 0.10 & 0.22 & 0.26 & 0.24 & 0.21 \\
\hline \multicolumn{9}{|l|}{ Subscale 7 - Recording of information } \\
\hline General information & 0.12 & 0.08 & 0.10 & 0.12 & 0.17 & 0.01 & 0.43 & 0.11 \\
\hline Diagnosis of diabetes & 0.62 & 0.48 & 0.34 & 0.46 & 0.68 & 0.56 & 0.79 & 0.59 \\
\hline Presence/ absence of co-morbidities & 0.18 & 0.27 & 0.35 & 0.46 & 0.44 & 0.38 & 0.57 & 0.40 \\
\hline Presence/ absence of risk factors & 0.39 & 0.28 & 0.32 & 0.35 & 0.53 & 0.38 & 0.72 & 0.40 \\
\hline Physical activity & 0.60 & 0.54 & 0.31 & 0.56 & 0.69 & 0.57 & 0.79 & 0.68 \\
\hline \multicolumn{9}{|l|}{ Subscale 8 - Functional aspects } \\
\hline Polite reception by health worker & 0.44 & 0.49 & 0.32 & 0.33 & 0.53 & 0.49 & 0.49 & 0.71 \\
\hline Service provision according to appointment & 0.47 & 0.42 & 0.35 & 0.36 & 0.55 & 0.56 & 0.44 & 0.61 \\
\hline Instruction for patients & 0.38 & 0.42 & 0.18 & 0.23 & 0.47 & 0.42 & 0.51 & 0.70 \\
\hline MO Communicates well with the patient & 0.57 & 0.60 & 0.67 & 0.45 & 0.59 & 0.49 & 0.59 & 0.75 \\
\hline Date and time for next clinic visit & 0.16 & 0.27 & 0.26 & 0.20 & 0.26 & 0.25 & 0.32 & 0.61 \\
\hline
\end{tabular}

1- Medical Officer, 2- Angiotensin Converting Enzyme Inhibitor or Angiotensin Receptor Blocker, 3- Body Mass Index, 4Electrocardiogram, 5- Peripheral Arterial Disease, 6- Health Education, 7- Nursing Officer

$\mathrm{n}=100$ for all correlation coefficients.

Item scale correlations with its own scale for item convergent validity are shown in bold typing. 
Table 3. Mean scores of service quality by the category of hospital (Secondary or Tertiary)

\begin{tabular}{|c|c|c|c|c|c|c|}
\hline \multirow[t]{2}{*}{ Subscale } & \multicolumn{2}{|c|}{$\begin{array}{l}\text { Secondary } \\
\mathrm{N}=\mathbf{5 0}\end{array}$} & $\begin{array}{l}\text { Tertiar } \\
\mathbf{N}=\mathbf{5 0}\end{array}$ & & \multirow[t]{2}{*}{ p value } & \multirow[t]{2}{*}{$\begin{array}{lr}\text { Mean } & \text { difference } \\
(95 \% & \text { confidence } \\
\text { interval) } & \end{array}$} \\
\hline & Mean & SD & Mean & SD & & \\
\hline Routine care & 10.1 & 3.5 & 15.5 & 1.7 & $<0.001$ & $5.4(4.3$ to 6.5$)$ \\
\hline Glycaemic control & 5.6 & 0.7 & 7.0 & 1.3 & $<0.001$ & $1.4(1.1$ to 1.9$)$ \\
\hline Blood Pressure and lipid control & 9.0 & 1.7 & 9.9 & 1.3 & $<0.001$ & $0.9(0.3$ to 1.5$)$ \\
\hline Weight control & 5.0 & 2.5 & 8.7 & 3.2 & $<0.001$ & $3.7(2.6$ to 4.8$)$ \\
\hline Annual Screening & 7.8 & 1.6 & 16.1 & 1.9 & $<0.001$ & $8.3(7.6$ to 9.1$)$ \\
\hline Patient empowerment & 12.4 & 2.2 & 22.5 & 4.6 & $<0.001$ & $10.1(8.6$ to 11.5$)$ \\
\hline Recording of information & 9.8 & 1.1 & 13.1 & 1.3 & $<0.001$ & $3.3(2.8$ to 3.8$)$ \\
\hline Functional aspects & 8.6 & 0.9 & 10.9 & 1.3 & $<0.001$ & $2.3(1.9$ to 2.8$)$ \\
\hline
\end{tabular}

Table 4. Means, standard deviations, Cronbach's alpha and intra-class correlation coefficients of subscales

\begin{tabular}{lllll}
\hline Subscales & $\begin{array}{l}\text { No. of } \\
\text { items }\end{array}$ & Mean \pm SD & Cronbach's alpha & $\begin{array}{l}\text { ICC among raters } \mathbf{( 9 5 \%} \\
\text { confidence interval) }\end{array}$ \\
\hline Routine care & 6 & $12.8 \pm 3.8$ & $0.86^{*}$ & $0.98(0.97-0.99)$ \\
Glycaemic control & 3 & $6.3 \pm 1.3$ & 0.52 & $0.95(0.87-0.99)$ \\
BP and lipid control & 5 & $12 \pm 1.8$ & 0.56 & $0.98(0.97-0.99)$ \\
Weight management & 4 & $6.8 \pm 3.4$ & $0.93^{*}$ & $0.98(0.96-0.99)$ \\
Annual screening & 6 & $11.9 \pm 4.6$ & $0.92^{*}$ & $0.93(0.82-0.98)$ \\
Patient empowerment & 10 & $17.4 \pm 6.2$ & $0.75^{*}$ & $0.95(0.87-0.99)$ \\
Recording of information & 5 & $11.5 \pm 2.0$ & $0.70^{*}$ & $0.98(0.97-0.99)$ \\
Functional aspects & 5 & $12.2 \pm 1.9$ & $0.70^{*}$ & $0.90(0.74-0.97)$ \\
\hline Total & $\mathbf{4 4}$ & $\mathbf{9 1 . 1} \pm \mathbf{2 0 . 0}$ & $\mathbf{0 . 9 6}$ &
\end{tabular}

* Subscales with good internal consistency of $\geq 0.7$ (Cronbach's alpha $\geq 0.7$ ).

Table 5. Quality of services of hospitals according to the subscales

\begin{tabular}{lllll}
\hline \multirow{2}{*}{ Subscale } & \multicolumn{2}{l}{ Performance of clinics } & & C \\
\cline { 2 - 5 } & A & B & moderate & moderate \\
\hline Routine care & poor & poor & moderate & good \\
Glycaemic control & poor & poor & moderate & moderate \\
BP and lipid control & poor & poor & moderate & moderate \\
Weight management & poor & poor & moderate & good \\
Annual screening & poor & poor & moderate & moderate \\
Patient empowerment & poor & poor & moderate & good \\
Recording of information & poor & poor & moderate & good \\
Functional aspects & poor & Mean &
\end{tabular}

Good: score $\geq$ Mean + SD, Moderate: score $\geq$ Mean but $<$ Mean + SD, Poor: score $<$ Mean.

\section{Discussion}

The purpose of this study was to develop a valid measure for assessment of quality of care provided for patients with DM attending state clinics. Results suggest that Care for Diabetes Quality of Services (CDQS) checklist 
developed in this study yields a valid and reliable tool to assess the quality of services provided for follow up care of patients with DM. CDQS is a checklist to observe the quality of services in diabetic and medical clinics. Observations give more information compared to other data collection techniques like interviews or questionnaires (Moser \& Kalton, 1971). Thus observation was considered superior to interviewing in determining how well the services were provided.

A cross sectional study was considered suitable for validation of CDQS. Homogeneity of the checklist was evident via item total correlation and Cronbach's alpha methods. Construct validity of CDQS was accomplished by multi-trait scaling analysis and comparison of known groups (Peter, 1981). In the present study, 43 items (98.8\%) showed satisfactory item convergent and item discriminant validity. However, item 'advice on dosage and frequency of medicines' demonstrated lower correlation and cross loading. Nevertheless, it was decided to retain the item as proper advice on medication is essential for improved medication adherence. Furthermore, pharmacists are expected to play a major role in self-management support, drug related problem identification, medication review and diabetic education (Krass, Costa, \& Dhippayom, 2015). Based on hypothesis that tertiary level hospitals provide better care compared to other levels, CDQS demonstrated the ability of differentiating service quality difference $(\mathrm{p}<0.05)$ between secondary and tertiary level hospitals via known groups method. The same method was used previously by Samaranayaka (Samaranayake \& Seneviratne, 2012) in validation of Maslach Burnout Inventory - Human Services Survey, Megans (Megens, Harris, Backman, \& Hayes, 2007) for Harris Infant Neuromotor Test which was used as a screening tool. Criterion validity was not carried out due to absence of a gold standard.

The advantage of CD QS is that it measures both functional and technical quality simultaneously enabling insight into major gaps and immediate remedial action. This was the first study that attempted to incorporate both technical and functional aspects of care for DM into a single instrument in order to achieve the target outcome. Many of the studies and internationally agreed performance indicators are based on clinical records and no in depth information is available to identify the deficiencies (De Berardis et al., 2004; Kanchanaphibool, Hirunrassami, \& Tongpugdee, 2009; Suwattee, Lynch, \& Pendergrass, 2003). In line with national and international guidelines of diabetes care, we included preventive measures such as screening and testing for complications of DM. Efforts were taken to include evidence based low cost interventions for controlling modifiable risk factors such as weight control and blood pressure control in CD QS which can be implemented in low resource settings such as Sri Lanka. Recording of smoking status, physical activity and other risk factors under general information were considered important as that will enhance insight into the risk burden and subsequent intervention. Patient empowerment was considered essential as it facilitates inculcating healthy life style practices of the patient as well as immediate family members as they are at high risk of DM.

Unlike with many of the available performance measures for quality of care, CD QS used in the present study demonstrated adequate validity, reliability, simplicity and clarity. When considering clarity, the clarity increases due to the availability of the standards for a data collector or a supervisor to look through and decide on the score. This minimizes inter-observer bias and shows practice variation in service provision. The time taken to fill the CD QS checklist did not vary according to the data collector as well. Outcome measures such as proportion meeting the target $\mathrm{HbA1C}$, blood pressure and blood lipid levels too could be utilized as service quality measures, there are many confounding factors for achieving those targets.

Hence CD QS provides health planners and providers with an objective tool to measure quality. Along with the facility survey, service gaps associated with deficiency of human resources and other facilities such as infrastructure, availability of laboratory facilities, adequate supply of medicines, poor organization of clinic activities could be identified and effective measures implemented to improve the quality of services and facilities of clinics for patients with DM. Given that Sri Lanka is currently in the preliminary stage of electronic health information system and poor implementation of outpatient data recording system warrant timely surveys to assess the service quality.

\subsection{Limitations}

Convenient sampling within clinics may result in inadequate representation of the total clinic population compared to systematic or random sampling which could be overcome by adequate number of data collectors to follow each recruited participant. Another limitation of this study was allocating equal scores for each item. Measuring blood glucose, measuring blood pressure, intervention for high blood glucose, history taking and weight monitoring could have been weighted according to their importance. However all services were considered equally essential in the present study to achieve overall quality. Presence of an observer is subjected to varying degrees of observation effect as subjects are aware of being assessed and thought to perform better or 
worse than what they practice every day. However the nature of the observation effect is widely considered to be in the direction of overestimating the performance. On the other hand the performance of a health provider may vary from one patient to another and day to day depending on the characteristics of the patient and other situational factors namely the total number of patients to be seen, presence of other providers and availability of drugs and supplies. Therefore multiple measurements of provider-patient interaction and performance of the same task have to be considered to obtain a reliable indication of usual performance.

Outcome indicators such as blood glucose (HbA1C) level, blood pressure, serum lipid level may be incorporated when determining the total quality.

\section{Conclusions}

The findings provide a valid method of assessing service quality for DM at outpatient setting in Sri Lanka. CDQS can be used to identify service gaps over the time. Thus development of the instrument provides an opportunity for ongoing assessment and improving quality of care for patients with DM. Further testing and application is recommended for implementation of the tool in different settings and assessing the impact.

List of abbreviations: Diabetes mellitus-DM, Care for DM Quality of services-CD QS, United States of America-USA.

\section{Ethics Approval and Consent to Participate}

Written permission was obtained from health authorities prior to data collection and ethical approval was granted by the Ethics Review Committee, Faculty of Medical Sciences, University of Sri Jayewardenapura, Sri Lanka.

\section{Consent for Publication}

Not applicable as no individual person's data of any form (including individual details, images or videos) have been included in the manuscript.

\section{Availability of Data and Material}

Data is not publicly available. There is no electronic health information system for outpatient (clinic) care in Sri Lanka.

\section{Competing Interests Statement}

The authors declare that there are no competing or potential conflicts of interest.

\section{Funding}

Funds were obtained from 'World Health Organization, country office, Sri Lanka' for data collection (payments for preintern Medical Officers). Prof Andre Renzaho is supported by an ARC future fellowship (FT110100345). Professor Chris Reid is supported by an NHMRC Senior Research Fellowship (1045862).

\section{Author's Contributions}

NT designed the study, collected the data, analysed and prepared the first draft of the manuscript, CR reviewed the manuscript and serves as a guarantor for the contents of the paper, PF contributed to the methods and developing instruments, $\mathrm{BB}$ contributed to the analysis and reviewed the manuscript, $\mathrm{CW}$ contributed to the concept and data collection, AR contributed to the discussion and reviewed the manuscript, All authors approved the final manuscript.

\section{Acknowledgements}

Authors would like to acknowledge: Endocrinologists, Medical Specialists, Public Health Specialists and Medical Administrators in Sri Lanka for their technical assistance in developing the study instrument, World Health Organization, country office, Sri Lanka for financial assistance in data collection.

\section{References}

American Diabetes Association. (2012). Standards of Medical Care in Diabetes. Diabetes care, 35(supplement 1), S11-S63. https://doi.org/10.2337/dc12-s011

Campbell, S. M., Roland, M. O., \& Buetow, S. A. (2000). Defining quality of care. Social Science \& Medicine, 51(11), 1611-1625. https://doi.org/10.1016/S0277-9536(00)00057-5

De Berardis, G., Pellegrini, F., Franciosi, M., Belfiglio, M., Di Nardo, B., Greenfield, S., . . Tognoni, G. (2004). Quality of Care and Outcomes in Type 2 Diabetic Patients A comparison between general practice and diabetes clinics. Diabetes care, 27(2), 398-406. https://doi.org/10.2337/diacare.27.2.398 
Donabedian, A. (1988). The quality of care. How can it be assessed? Jama, 260(12), 1743-1748.

Families USA, \& The Voice for Health Care Consumers. (2014). Measuring Health Care Quality: An Overview of Quality Measures. Retrieved from $\mathrm{http} / /$ familiesusa.org/product/measuring-health-care-quality-overview-quality-measures

Grandy, S., \& Fox, K. M. (2008). EQ-5D visual analog scale and utility index values in individuals with diabetes and at risk for diabetes: Findings from the Study to Help Improve Early evaluation and management of risk factors Leading to Diabetes (SHIELD). Health and quality of life outcomes, 6(1), 18. https://doi.org/10.1186/1477-7525-6-18

Grönroos, C. (1984). A Service Quality Model and its Marketing Implications. European Journal of Marketing, 18(4), 36-44. https://doi.org/10.1108/EUM0000000004784

Hays, R. D., Hayashi, T., Carson, S., \& Ware, J. E. (1988). User's guide for the Multitrait Analysis Program (MAP) (Vol. 2786): Rand Corporation Santa Monica, CA.

International Diabetes Federation. (2013). IDF Clinical Practice Guidelines. Retrieved from www.idf.org

Kanchanaphibool, I., Hirunrassami, S., \& Tongpugdee, P. (2009). Quality indicators of diabetes care in practice. Southeast Asian Journal of Tropical Medicine and Public Health, 40(5), 1074.

Katulanda, P., Constantine, G., Mahesh, J., Sheriff, R., Seneviratne, R., Wijeratne, S., . . Matthews, D. 2008). Prevalence and projections of diabetes and pre-diabetes in adults in Sri Lanka-Sri Lanka Diabetes, $\begin{array}{lllll}\text { Cardiovascular Study (SLDCS). Diabetic } & \text { Medicine, 25(9), }\end{array}$ https://doi.org/10.1111/j.1464-5491.2008.02523.x

Katulanda, P., Rathnapala, D., Sheriff, R., \& Matthews, D. (2012). Province and ethnic specific prevalence of diabetes among Sri Lankan adults. Sri Lanka Journal of Diabetes Endocrinology and Metabolism, 1(1), 2-7. https://doi.org/10.4038/sjdem.v1i1.4180

Kiflie, Y., Jira, C., \& Nigussie, D. (2011). The Quality of Care Provided to Patients with Chronic Non-Communicable Diseases: A Retrospective Multi-Setup Study in Jimma Zone, Southwest Ethiopia. Ethiopian Journal of Health Sciences, 21(2), 119-130. https://doi.org/10.4314/ejhs.v21i2.69052

Krass, I., Costa, D., \& Dhippayom, T. (2015). Development and validation of the Attitudes to Pharmacist Services for Diabetes Scale (APSDS). Res Social Adm Pharm, 11(1), 74-84. https://doi.org/10.1016/j.sapharm.2014.04.005

McGlynn, E. A., Asch, S. M., Adams, J., Keesey, J., Hicks, J., DeCristofaro, A., \& Kerr, E. A. (2003). The quality of health care delivered to adults in the United States. New England journal of medicine, 348(26), 2635-2645. https://doi.org/10.1056/NEJMsa022615

McQuestion, M. J. (2006). Quality of Care. Retrieved from http://ocw.jhsph.edu/courses/immunizationPrograms/PDFs/Lecture7.pdf website:

Megens, A. M., Harris, S. R., Backman, C. L., \& Hayes, V. E. (2007). Known-Group Analysis of the Harris Infant Neuromotor Test. Physical therapy, 87, 164-169. https://doi.org/10.2522/ptj.20060096

Ministry of Healthcare and Nutrition Sri Lanka. (2007). National Guidelines: Clinical Practice Guidelines. Management of Diabetes Mellitus.

Moser, C. A., \& Kalton, G. (1971). Survey methods in social investigation (2 ed.). London: Heinemann Educational.

National Health Services. (2015). NHS outcomes framework - 5 domins resources. Retrieved from https://digital.nhs.uk/data-and-information/publications/ci-hub/nhs-outcomes-framework

Parasuraman, A., Zeithaml, V. A., \& Berry, L. L. (1985). A conceptual model of service quality and its implications for future research. The Journal of Marketing, 41-50.

Peabody, J. W., Taguiwalo, M. M., Robalino, D. A., \& Frenk, J. (2006). Improving the quality of care in developing countries. In D. T. Jasmin, J. G. Breman, A. R. Measham, \& A. George (Eds.), Disease control priorities in developing countries (2nd ed., pp. 1293-1308). New York: Oxford University Press and The World Bank.

Peter, J. P. (1981). Construct validity: a review of basic issues and marketing practices. Journal of Marketing Research, 133-145. https://doi.org/10.1177/002224378101800201 
Rannan-Eliya, R., Anuranga, C., Brearley, L., Elwalagedara, R., \& Abeykoon, A. (2010). An Assessment of the Burden, Issues and Policy Options in Curative Care Services Delivery and Noncommunicable Diseases in Sri Lanka. In Technical Report series No1. Sri Lanka: Institute for Health Policy.

Samaranayake, D., \& Seneviratne, S. D. A. (2012). Validity of the Maslach Burnout Inventory-Human Services Survey among Sri Lankan Nursing Officers. Psychological Studies, 57(1), 101-111. https://doi.org/10.1007/s12646-011-0135-5

Streiner, D., \& Norman, G. (2003). Health measurement scales: A practical guide to their development and use (3 ed.). Oxford: Oxford University Press

Suwattee, P., Lynch, J. C., \& Pendergrass, M. L. (2003). Quality of care for diabetic patients in a large urban public hospital. Diabetes care, 26(3), 563-568. https://doi.org/10.2337/diacare.26.3.563

UK Prospective Diabetes Study Group. (1998). Tight blood pressure control and risk of macrovascular and microvascular complications in type 2 diabetes: UKPDS 38. BMJ: British Medical Journal, 317(7160), 703. https://doi.org/10.1136/bmj.317.7160.703

Wild, S., Roglic, G., Green, A., Sicree, R., \& King, H. (2004). Global prevalence of diabetes estimates for the year 2000 and projections for 2030. Diabetes care, 27(5), 1047-1053. https://doi.org/10.2337/diacare.27.5.1047

Wisniewski, M., \& Wisniewski, H. (2005). Measuring service quality in a hospital colposcopy clinic. International Journal of Health Care Quality Assurance, 18(3), 217-228. https://doi.org/10.1108/09526860510594776

World Health Organization. (2002). Innovative care for chronic conditions: building blocks for actions: global report.

World Health Organization. (2004). Diabetes action now: An initiative of the World Health Organization and the International Diabetes Federation.

World Health Organization. (2006). Quality of care: a process for making strategic choices in health ystems. Geneva: World Health Organization.

\section{Copyrights}

Copyright for this article is retained by the author(s), with first publication rights granted to the journal.

This is an open-access article distributed under the terms and conditions of the Creative Commons Attribution license (http://creativecommons.org/licenses/by/4.0/). 